Revista Brasileira de História \& Ciências Sociais - RBHCS

Vol. $8 \mathrm{~N}^{\mathrm{O}}$ 16, Julho - Dezembro de 2016

\title{
"Não nos calaremos, somos a sua consciência pesada; a Rosa Branca não os deixará em paz!": Uma análise da resistência nos panfletos do grupo Rosa Branca
}

\section{"We will not be silent, we are your bad conscience; the White Rose will not leave you in peace!": an analysis of the resistance in the leaflets of the White Rose group}

Maria Visconti*

Resumo: Rosa Branca foi um grupo de resistência passiva que surgiu em Munique, na Alemanha, entre os anos de 1942 e 1943. Seus membros eram um professor e estudantes da Universidade de Munique. O grupo contou com os panfletos como forma de disseminar a resistência ao regime nazista, sem que seus integrantes fossem descobertos. O presente trabalho busca uma análise da resistência proposta pelo Rosa Branca, mobilizando conceitos como: resistência passiva, culpa, responsabilidade e liberdade. Para isso, será lançado um olhar sobre a memória produzida no pós-guerra sobre esse grupo, para compreender a complexidade do regime totalitário, utilizando como aporte teórico os autores Hannah Arendt e Zygmunt Bauman. A proposta é de não romantizar a resistência antinazista e compreender as singularidades dos jogos políticos dos atores e as ondas entre os conceitos.

Palavras-chave: Rosa Branca. Panfletos. Totalitarismo.

Abstract: The White Rose was a passive resistance group that rose in Munich, in Hitler's Germany, between the years of 1942 e 1943. The members of this group were students and a professor from Munich University. The group used leaflets as a way to pass their ideas of resistance against the Nazi government, but at the same time they were careful not to be discovered. This paper tries to make an analysis of the resistance of the White Rose, using concepts such as: passive resistance, guilty, responsibility and freedom. For that effect, I will take a closer look in the memory produced in the afterwar of this group, in order to understand the complexity of the totalitarian regime, using

\footnotetext{
* Mestranda em História e Culturas Políticas pela Universidade Federal de Minas Gerais.
} 


\section{Revista Brasileira de História \& Ciências Sociais - RBHCS}

Vol. $8 \mathrm{~N}^{\circ}$ 16, Julho - Dezembro de 2016

as theoretical support the authors Hannah Arendt and Zygmunt Bauman. The purpose here is to not romanticize the antinazi resistance and to understand the singularities of the political set of the authors and the waves among the concepts.

Key-words: White Rose. Leaflets. Totalitarianism.

\section{Introdução}

Uma postura muito recorrente na historiografia é a de romantizar os resistentes, principalmente em se tratando dos resistentes ao regime nazista. Geralmente, estes são apresentados como corajosos, heróis e destemidos, que lutaram contra um regime opressor sem temer a morte; ou como grandes pregadores da liberdade e da democracia, que batalharam por um futuro melhor. No entanto, é fundamental entender a constituição desses atores políticos quando pregam sua resistência. Fugindo de um viés conservador que nega o heroísmo da resistência, pretendo relativizar o empreendimento desses atores políticos, buscando evitar o uso de conceitos binários como resistência $\mathrm{x}$ colaboração.

A principal fonte sobre a história da Rosa Branca é o livro de Inge Scholl, irmã de Sophie e Hans Scholl, membros do grupo. É importante pontuar que a obra foi escrita entre 1947 e 1952, no processo de construção de memória da Alemanha no pós-guerra. A postura dos Aliados inicialmente foi a de não fazer uma diferenciação entre alemães e nazistas, querendo mostrar para o mundo e principalmente para os alemães, o que "eles" haviam feito. A culpabilização do povo alemão foi muito forte e presente durante esse período, o que Hannah Arendt chama de "processo de desnazificação" (ARENDT, 2008). A população civil passou a ter acesso ao horror e o discurso produzido era o de que todos tinham feito aquilo, uma ideia de culpa coletiva.

O livro de Inge aparece conjuntamente com uma nova onda de fontes para desmistificar a ideia de que todos os alemães eram nazistas. Neste sentido, é um livro que deve ser lido como um testemunho da época, como um trabalho de memória, um esforço para mostrar que houve resistência e que era possível resistir. Inge apresenta o 


\section{Revista Brasileira de História \& Ciências Sociais - RBHCS}

Vol. $8 \mathrm{~N}^{\mathrm{o}}$ 16, Julho - Dezembro de 2016

Rosa Branca como um grupo corajoso e destemido, que estava disposto a morrer por seus ideais. Sua narrativa, muitas vezes idealiza esses estudantes:

“Alguns poucos estudantes assumiram o peso de agir sob a onipresença
da ditadura; aceitaram a solidão, não puderam se abrir nem mesmo com
a família; aceitaram a limitação imposta pela onipotência do Estado;
contentaram-se em provocar rachaduras ao invés de grandes explosões.
Não quiseram e não puderam ir além e estavam prontos a pagar com
tudo o que eram e tinham" (SCHOLL, 2013, p. 120)

Esta visão de que era possível resistir pode levar a conclusões muito equivocadas e injustas. Apontar exemplos como a Rosa Branca (que eram uma minoria entre a população) para culpar os que não se revoltaram é incoerente, pois não havia um espaço político para resistir dentro do governo nazista. Qualquer ato de resistência ou de discordância poderia - e era, na maioria das vezes - punido com a morte, o que deixa o campo de possibilidades muito restrito. De acordo com os dados de Peter Hoffman, cerca de 3 milhões de alemães foram presos em algum tipo de campo de concentração ou em prisões tradicionais por motivos políticos, dos quais 800.000 foram presos por resistir ativamente ao regime. Neste mesmo período, 10.000 alemães foram mortos por apresentarem alguma forma de resistência (HOFFMAN, 2001).

A resistência ativa ao regime nazista foi eliminada pouco depois que Hitler assumiu o poder, e já em 1933, grupos como comunistas e liberais foram levados à campos de concentração ou prisões. Neste mesmo ano foi emitido um decreto emergencial que, entre outras coisas, proibia a distribuição de qualquer artigo impresso, fosse ele um jornal, um pôster ou um panfleto, com o perigo de prisão imediata dos autores do artigo e de qualquer pessoa que soubesse deste tipo de atividade ilegal e não a denunciasse. Este decreto também proibia reuniões ao ar livre que pudessem "colocar em perigo a segurança pública" (HOFFMAN, 2001).

\section{A Rosa Branca}

O grupo Rosa Branca surgiu em Munique, na Alemanha, entre os anos de 1942 e 1943 e propunha a resistência pacífica contra o regime de Hitler, principalmente por meio da sabotagem aos mecanismos do partido. Disseminavam essa ideia de resistência por meio de panfletos que foram distribuídos pela cidade e também por outros 


\section{Revista Brasileira de História \& Ciências Sociais - RBHCS}

Vol. $8 \mathrm{~N}^{\circ}$ 16, Julho - Dezembro de 2016

municípios da Alemanha como Hamburgo, Berlim, Colônia, Bonn, Frankfurt e Saarbrücken. Nessas outras cidades foram formadas novas células do Rosa Branca com a ajuda de amigos dos membros de Munique. Todos os membros foram encontrados pela Gestapo, condenados por crimes de alta traição, e assassinados. É importante fazer uma análise do conteúdo de seus panfletos, dos conceitos mobilizados (liberdade, resistência, culpa) e também da constituição política do grupo.

Eles produziram seis panfletos no total ${ }^{1}$, sendo, cada um deles, de no máximo duas páginas e geralmente possuíam citações de filósofos, poetas ou da Bíblia. A Rosa Branca não possuía nenhuma forma de financiamento e eram cuidadosos para que as pessoas que recebiam seus panfletos também não fossem descobertas. Geralmente os panfletos eram colocados nas caixas de correio de pessoas escolhidas de maneira aleatória. Seus membros conseguiram comprar uma máquina copiadora de segunda mão e uma máquina de escrever, e dividiam os custos dos envelopes, selos e tinta. Manfred Eickemeyer, um arquiteto amigo de Hans, deixou o grupo usar o estúdio de sua casa para fazer as cópias dos panfletos (DUMBACH; NEWBORN, 2007, p. 57- 8). Os motivos da escolha do nome "Rosa Branca" ainda permanecem obscuros, mas acredita-se que seja uma forma de representação da pureza e inocência frente ao mal, mais um símbolo artístico do que político². Os quatro primeiros panfletos foram escritos por Hans Scholl e Alexander Schmorell em aproximadamente junho de 1942; o quinto contou também com a participação de Willi Graf e Kurt Huber e foi distribuído em janeiro de 1943; e o sexto e último panfleto foi escrito por Kurt Huber e distribuído na Universidade de Munique em 18 de fevereiro de 1943 por Hans e Sophie Scholl, quando ambos foram presos pela Gestapo. Esta última tiragem girou em torno de 3400 panfletos jogados no pátio interno da Universidade. O grupo também pichou as paredes de vários locais de Munique

\footnotetext{
${ }^{1}$ Atualmente é conhecido o excerto do sétimo panfleto que estava ainda sendo produzido por Christoph Probst, e que não chegou a ser distribuído. Hans Scholl rasgou o rascunho do mesmo quando foi preso pela Gestapo, em 18 de fevereiro de 1943, mas esta foi capaz de recuperar e reconstruir os pedaços do panfleto. O excerto está disponível em: SCHOLL, Inge. A Rosa Branca: A história dos estudantes alemães que desafiaram o nazismo. São Paulo: Editora 34, 2013, pp. 233-4.

${ }_{2}$ Durante o interrogatório feito pela Gestapo, Hans Scholl afirma que o nome deriva de uma novela espanhola ele havia lido. Existiu, de fato, um livro publicado em Berlim em 1931 pelo autor alemão B. Traven, chamado "The White Rose". O livro trata da exploração de uma terra indígena no México por uma companhia de petróleo americana, supostamente baseado em uma história real, e há possibilidade de Hans e Alex o terem lido, mas nada foi confirmado.
} 


\section{Revista Brasileira de História \& Ciências Sociais - RBHCS}

Vol. $8 \mathrm{~N}^{\mathrm{o}}$ 16, Julho - Dezembro de 2016

(inclusive na Universidade) em fevereiro de 1943 as inscrições "Fora Hitler"; "Hitler, assassino em massa" e "Liberdade" (DUMBACH; NEWBORN, 2007).

Todos os membros do grupo foram encontrados pela Gestapo e executados por crime de alta traição, inclusive os membros das outras células que foram criadas em cidades vizinhas. Christoph Probst, Hans e Sophie Scholl foram executados em 23 de fevereiro de 1943, enquanto Willi Graf, Alexander Schmorell e o professor Kurt Huber, em 13 de julho do mesmo ano3 ${ }^{3}$ A maioria dos panfletos se dirigia ao povo alemão, mas o sexto panfleto - que foi escrito pelo professor Kurt Huber - era voltado mais especificamente aos estudantes universitários. Entretanto, apesar de se dirigirem à população alemã, em geral, os panfletos possuíam uma linguagem acadêmica, afinal, o grupo surgiu dentro do meio universitário. Esta linguagem, provavelmente, não resultaria em uma identificação com a totalidade da população - essa foi justamente a crítica que Falk Harnack, amigo de Hans, fez ao ler um dos panfletos (DUMBACH; NEWBORN, 2007, p. 6-8).

Tendo isto em mente, é possível fazer uma análise mais específica da Rosa Branca e de seus ideais. Pode-se dizer que era um grupo conservador e religioso, sendo alguns membros cristãos e outros protestantes vindos de famílias tradicionais da burguesia alemã. Uma das características mais interessantes do grupo, era a de que não propunham e nem defendiam nenhuma forma de governo - inclusive, afirmam que todas as formas conhecidas são utópicas. Eles queriam tirar Hitler do poder pois consideravam seu governo tirânico, mas não defendiam a democracia ou nenhuma outra forma de governo. Este é um argumento importante para compreender a conjuntura do grupo e perceber como a resistência pode ser libertária, mas também conservadora:

"Todas as formas ideais de Estado são utopias. Um Estado não pode ser construído de maneira puramente teórica; ele precisa crescer, amadurecer, assim como um indivíduo. Mas não se deve esquecer de que já existia uma forma rudimentar de Estado nos primórdios de cada civilização. A família é tão antiga quanto o próprio homem e a partir dessa convivência inicial, o homem, como ser racional, criou para si um Estado cujo fundamento é a Justiça e cuja lei suprema deve ser o Bem Comum. O Estado deve representar uma analogia da ordem divina e, por

3 As sentenças de morte podem ser encontradas em: Inge. A Rosa Branca: A história dos estudantes alemães que desafiaram o nazismo. São Paulo: Editora 34, 2013, pp. 121-138. 


\section{Revista Brasileira de História \& Ciências Sociais - RBHCS}

Vol. $8 \mathrm{~N}^{\circ}$ 16, Julho - Dezembro de 2016

fim, se aproximar de seu modelo, a mais alta de todas as utopias, que é a civitas Dei" (SCHOLL, 2013, p. 99)

É relevante esclarecer que a Rosa Branca possuiu duas fases, que foram muito distintas entre si. A primeira, que se deu entre junho e julho de 1942, contou com os quatro primeiros panfletos, denominados "Panfletos da Rosa Branca". Nessa primeira fase, é notável uma influência mais religiosa e apocalíptica nos escritos: Hitler é associado ao Anticristo, e a luta ao Nacional Socialismo é, fundamentalmente, uma luta contra o demônio.

“Toda palavra que sai da boca de Hitler é mentira. Quando ele fala em paz, está pensando em guerra, e quando ele pronuncia - de maneira mais sacrílega possível - o nome do Todo Poderoso, está pensando no poder do Mal, no Anjo Caído, em Satã. Sua boca é a garganta fétida do inferno, e seu poder é fundamentalmente réprobo" (SCHOLL, 2013, p. 103-104)

Nessa fase, todos os panfletos contam com citações de filósofos, poetas ou da Bíblia, algumas relativamente extensas (o primeiro panfleto, por exemplo, contém um excerto de um livro de Friedrich Schiller e uma longa citação de Goethe), e é perceptível uma linguagem menos propositiva, mais rebuscada e com apelo a um setor mais intelectualizado da Alemanha. Inge Scholl, ao tratar dos objetivos da Rosa Branca, afirma:

“Tinham um senso aguçado para questões políticas, o qual porém não era definido em termos ideológicos, mas sociológicos - seu interesse principal era a sociedade. Sua primeira preocupação era o fracasso da intelectualidade alemã, do qual eles tinham plena consciência. Por isso, usaram a linguagem da burguesia culta e se referiram aos grandes nomes da cultura alemã, como Schiller e Goethe, sobretudo no primeiro panfleto. Tentaram tocar principalmente pessoas cultas. Tentaram despertar na intelectualidade alemã uma consciência pesada e, por fim, suscitar o protesto interno e externo. [...] Meu irmão partia do pressuposto de que a intelectualidade tinha uma responsabilidade maior devido a seus conhecimentos. Mas Hans não queria só que ela refletisse, ela deveria reforçar o seu papel por meio do engajamento político e conquistar maior relevância na sociedade através de ações concretas"4 (SCHOLL, 2013, p. 118-119)

A segunda fase da Rosa Branca conta com dois panfletos, escritos entre novembro de 1942 e fevereiro de 1943, denominados: "Panfletos do Movimento de Resistência na Alemanha”. Esse intervalo entre julho e novembro de 1942 se deu, provavelmente,

4 Grifo meu; 


\section{Revista Brasileira de História \& Ciências Sociais - RBHCS}

Vol. $8 \mathrm{~N}^{\circ}$ 16, Julho - Dezembro de 2016

porque a maioria dos membros foram para o exterior prestar serviço obrigatórios 5 . Nesse segundo momento, a linguagem dos panfletos muda completamente, tornando-se mais direta e informativa, e não existem mais citações. A guerra se torna a principal temática, os panfletos são mais curtos, pragmáticos e a resistência proposta é mais clara e ativa. Neste sentido, é perceptível a influência de Kurt Huber na escrita: são denunciados os crimes da guerra, o fechamento das universidades e o controle ideológico e intelectual.

Especula-se que ao retornar para a Alemanha após o serviço obrigatório, os membros da Rosa Branca sentiram necessidade de expandir as atividades do grupo e de se unir a um movimento de resistência mais amplo. É neste momento que os estudantes criam novas células da Rosa Branca em outras cidades, ampliando a circulação dos panfletos e gerando uma movimentação financeira por meio de doações para custear a impressão de mais panfletos (DUMBACH; NEWBORN, 2007). Ainda no fim de 1942, Hans e Alex viajam para encontrar Falk Harnack, irmão de Arvid Harnack, que foi membro do movimento de resistência da Alemanha e assassinado. Esse encontro se deu para uma análise dos panfletos e de possíveis estratégias para a inserção da Rosa Branca em um movimento de resistência nacional, com sede em Berlim, bem como a ampliação das atividades do grupo. 6

Em 3 de fevereiro de 1943 foi o fim da batalha de Stalingrado, e o último panfleto, escrito por Kurt Huber, trata basicamente desse aspecto, buscando uma resistência estritamente estudantil. A linguagem deste panfleto é mais clara e a chamada para a luta contra o partido é feita para os universitários e a juventude alemã. A dominação ideológica do Nacional Socialismo por meio da Juventude Hitlerista, a SA e a SS são denunciadas, e eles se denominam "operários do intelecto":

\footnotetext{
5 Alex, Hans e Willi foram mandados para a Rússia para serviço médico compulsório no front, enquanto Sophie vai para o trabalho obrigatório em uma fábrica. Ver mais em: DUMBACH, Annette; NEWBORN, Jud. Sophie Scholl and the White Rose. USA: Oneworld, 2007.

6 "Whithin a matter of two months - from November 1942 to early January 1943 - the White Rose operation had been transformed from na isolated and quixotic action performed by idealistic and romantic students into na expanding network that was spreading through Southwest Germany, up to the Saarland, and was making tentativ but promising leaps into the North, to Hamburg, and, most important, Berlin" In: DUMBACH, Annette; NEWBORN, Jud. Sophie Scholl and the White Rose. USA: Oneworld, 2007, p. 121.
} 


\section{Revista Brasileira de História \& Ciências Sociais - RBHCS}

Vol. $8 \mathrm{~N}^{\circ}$ 16, Julho - Dezembro de 2016

"Para nós só existe um lema: a luta contra o partido! Abandonar as estruturas do partido que querem nos manter amordaçados politicamente! Sair dos auditórios dos sargentos e coronéis da SS e dos capachos do partido! Queremos a ciência verdadeira e a autêntica liberdade de espírito! Nenhuma ameaça conseguirá nos intimidar: nem mesmo o fechamento de nossas universidades! Trata-se da luta de cada um de nós pelo nosso futuro, nossa liberdade e honra em um Estado consciente de sua responsabilidade moral. [...] A reputação alemã ficará para sempre maculada se a juventude alemã não se elevar, não se vingar, não se redimir, não esmagar seus algozes e construir uma nova Europa espiritual, de uma vez por todas.

Universitárias! Universitários! O povo alemão olha para nós! Hoje, ele espera de nós o fim do terror nacional socialista pelo poder do espírito, assim como esperou em 1813 o fim do terror napoleônico. Beresina e Stalingrado estão em chamas no Leste, os mortos de Stalingrado nos invocam!

'Levanta, meu povo, já ardem as chamas!'

Nosso povo está em levante contra a escravização da Europa imposta pelo nacional socialismo, na confiança renovada de que a honra e a liberdade triunfarão!”7 (SCHOLL, 2013, p. 110-111)

\section{Os panfletos e seus conceitos}

Pensando mais especificamente nos panfletos da Rosa Branca, analisarei alguns conceitos que aparecem de maneira clara em seus escritos: os conceitos de culpa, liberdade e resistência.

A ideia de culpa do povo alemão perpassa grande parte dos panfletos. Os membros da Rosa Branca acreditavam que todos sabiam de tudo que estava acontecendo na Alemanha (apesar de não serem muito específicos no que seria esse "tudo") e que se recusavam a refletir sobre o assunto. Insistiam que não falavam nada de novo em seus panfletos, e que o povo alemão se encontrava em um sono profundo e que quanto mais se recusassem a acordar, maior seria a sua culpa. É interessante observar que quando o assassinato dos judeus é mencionado, o discurso não é no sentido de dizer que o antissemitismo é um problema. A Rosa Branca considera que assassinar judeus é repreensível porque eles são seres humanos, mas não fazem uma defesa da liberdade desse povo em uma perspectiva de lutar contra o antissemitismo. Não são mencionadas as propagandas antissemitas, os filmes, os cartazes e todo o vocabulário que trata os

7 Grifo meu. 


\section{Revista Brasileira de História \& Ciências Sociais - RBHCS}

Vol. $8 \mathrm{~N}^{\mathrm{o}}$ 16, Julho - Dezembro de 2016

judeus como se fossem vermes. Parece que esses estudantes consideravam que cada um poderia ter a sua opinião em relação ao "problema judaico", e que a objeção real, seria que matar outro ser humano é condenável - nada mais que isso.

"Não pretendemos abordar aqui a questão judaica, não queremos redigir nenhum discurso de defesa - não. Apenas como exemplo, queremos mencionar brevemente um fato: o fato de que, desde a tomada da Polônia, trezentos mil judeus foram assassinados naquele país da maneira mais bestial. Aqui vemos o mais terrível crime contra a dignidade humana, um crime sem precedentes em toda a história da humanidade. Pois os judeus também são seres humanos e - seja qual for a opinião de cada um sobre a questão judaica - foi contra seres humanos que esse crime foi cometido.” (SCHOLL, 2013, p. 96)

Para a Rosa Branca, as questões referentes ao nazismo atingiam a todos os alemães e deveria obrigar a todos a refletir. Mas, para eles, ninguém estava pensando sobre o assunto e "o povo alemão continua a dormir seu sono indiferente e estúpido, dando assim incentivo e oportunidade para os criminosos fascistas continuarem a sua devastação - e é o que eles estão fazendo" (SCHOLL, 2013, p. 96-97). Para os estudantes, não era apenas um direito, como um dever moral erradicar o governo de Hitler. Com relação à culpa, para eles, todos os indivíduos são culpados (uma visão diferente da de Hannah Arendt, que tratarei posteriormente):

"E ele [o povo alemão] não só deveria sentir compaixão pelas vítimas, não, muito mais que isso: deveria sentir sua parcela de culpa. Pois é a sua apatia que permite a essas pessoas sombrias agirem assim, ele dá suporte a esse 'governo' que fez recair sobre si uma culpa infinita; sim, ele é o culpado da existência desse governo! Todos querem ser absolvidos de sua parcela de culpa: é o que todos fazem, e depois voltam a dormir com a consciência tranquila. Mas ninguém pode ser absolvido: cada indivíduo é culpado, culpado, culpado!" (SCHOLL, 2013, p. 97)

Sobre a liberdade proposta pela Rosa Branca, ela se dá, principalmente, no sentido de liberdade de expressão. Eles associam o regime de Hitler à uma "ditadura do Mal" e entendem que lhes foi reprimido o direito de expressar opiniões contrárias ao governo. Ainda que não defendessem nenhuma forma de governo, demandam um Estado justo que "assegure tanto a liberdade de cada um quanto o bem de todos" (SCHOLL, 2013, p. 99), a "liberdade religiosa, [a] proteção de cada indivíduo contra a arbitrariedade de Estados autoritários e criminosos" (SCHOLL, 2013, p. 108) e a liberdade de espírito, de pensamento e ação: 


\section{Revista Brasileira de História \& Ciências Sociais - RBHCS}

Vol. $8 \mathrm{~N}^{\circ}$ 16, Julho - Dezembro de 2016

"Em nome de todo o povo alemão, exigimos que o Estado de Adolf Hitler nos devolva a liberdade pessoal, o bem mais precioso dos alemães, que ele nos roubou da maneira mais deplorável. Crescemos em um Estado em que toda a livre expressão da opinião foi amordaçada sem escrúpulos" (SCHOLL, 2013, p. 109)

O que o grupo propõe por resistência é a resistência pacífica, que eles entendem principalmente como boicote a todos os mecanismos do Partido Nazista. Acreditavam que se conseguissem unir um número grande de pessoas engajadas nessa tarefa, que se fosse possível produzir uma grande onda de revolta em todo o país, com esforço, o governo poderia ser eliminado. $\mathrm{O}$ terceiro panfleto de resistência trata deste tema de maneira mais clara:

“Como ele [o indivíduo] pode lutar contra o 'Estado' atual de forma mais eficaz possível, como pode lhe dar os golpes mais certeiros? Através da resistência passiva, sem dúvida. (...) Sabotagem às fábricas de armamentos e empresas fundamentais para a guerra, sabotagem a todas as assembleias, manifestações, festividades e organizações que forem promovidas pelo partido nacional-socialista. (...) Sabotagem a todas as áreas científicas e intelectuais que atuam a favor da continuidade da guerra presente - seja em universidades, escolas superiores, laboratórios, institutos de pesquisa ou escritórios técnicos. Sabotagem a todos os eventos de natureza cultural que possam aumentar o 'prestígio' dos fascistas aos olhos do povo. (...) Sabotagem a toda publicação, a todos os jornais que estão a soldo do 'governo' e que lutam pela sua ideologia e pela disseminação da mentira marrom” (SCHOLL, 2013, p. 101)

\section{Um diálogo entre Hannah Arendt e Zygmunt Bauman}

Para trabalhar os conceitos dos panfletos do Rosa Branca, é pertinente fazer uma reflexão acerca da problematização do uso de conceitos como aporte metodológico. Como argumenta Koselleck: "a história dos conceitos lida com o uso de linguagem específica em situações específicas, nas quais os conceitos são elaborados e usados por falantes específicos" (KOSELLECK, 1996, p. 62) ${ }^{8}$. É fundamental pensar tais conceitos no contexto histórico em que estão sendo utilizados, os campos sociais em que circulam e que são produzidos e reproduzidos. Como lembra Prost: "Historicizar os conceitos é identificar a temporalidade de que eles fazem parte; trata-se de um modo de aprender a contemporaneidade do não contemporâneo" (PROST, 2008, p. 130).

\footnotetext{
8 Citado em: JASMIN, Marcelo Gantus. História dos conceitos e teoria política e social: referências
} preliminares. Revista Brasileira de Ciências Sociais: vol. 20, $\mathrm{n}^{\circ} .57$, fevereiro de 2005, p. 32. 


\section{Revista Brasileira de História \& Ciências Sociais - RBHCS}

Vol. $8 \mathrm{~N}^{\circ}$ 16, Julho - Dezembro de 2016

Após mobilizar os conceitos dos panfletos da Rosa Branca, pretendo utilizar os autores Hannah Arendt e Zygmunt Bauman para analisar esses mesmos conceitos de forma mais aprofundada.

A filósofa política Hannah Arendt é minha principal fonte de análise teórica acerca das questões da liberdade e da política no governo Nacional Socialista. A autora trata do caráter apolítico dos regimes totalitários ${ }^{9}$ tendo em vista que, em sua forma de análise, o sentido primeiro e único da política é a liberdade. O que chamo aqui de um regime totalitário é um regime com um conjunto de características, tais como: o terror, a polícia secreta, o fim de todas as liberdades, o desprezo pela norma jurídica, o conflito constante entre Partido e Estado, a duplicação dos órgãos do Estado, os campos de concentração, o racismo, o isolamento dos indivíduos, a transformação dos indivíduos em seres supérfluos, a burocracia ${ }^{10}$.

Ao associar diretamente liberdade com política, Hannah Arendt entende que a liberdade se liga a alguma forma de ação. Segundo ela, o movimento dos regimes totalitários é baseado no fim da liberdade, seja ela no campo público ou no campo privado, de modo que este tipo de governo não poderia, então, ser considerado político. Para Arendt, é somente nos regimes totalitários que ocorre a "total eliminação da própria espontaneidade, isto é, da mais geral e elementar manifestação da liberdade humana" (ARENDT, 2011, p. 133).

A liberdade pública também é suprimida pelo governo nazista, assim como a liberdade política, com o regime de partido único. A discussão e o confronto de diferentes opiniões e de diferentes ideologias são totalmente excluídos da esfera de possibilidades do Nacional Socialismo. Como lembra Arendt: "sem um âmbito público politicamente assegurado, falta à liberdade o espaço concreto onde aparecer” (ARENDT,

\footnotetext{
9Hannah Arendt recebeu várias críticas ao seu livro Origens do Totalitarismo principalmente por tentar encaixar o conceito na situação soviética. Claude Lefort em seu livro A invenção democrática, tenta fazer justamente uma defesa do uso do conceito na situação soviética, criticando a postura da esquerda por não aceitar essa terminologia, e Jeffrey C. Isaac também faz uma defesa do uso do conceito em Arendt, Camus, and Modern Rebellion. Não tratarei aqui acerca da discussão da pertinência do conceito de totalitarismo, entretanto, pretendo utilizar esse conceito para compreender a noção de liberdade e de política dentro do regime nazista especificamente.

10 Para uma análise mais detalhada, ver: ARENDT, Hannah. Sobre a natureza do totalitarismo: uma tentativa de compreensão. In: Compreender: formação, exílio e totalitarismo (ensaios). São Paulo: Companhia das Letras; Belo Horizonte: Editora UFMG, 2008, pp. 347-380
} 


\section{Revista Brasileira de História \& Ciências Sociais - RBHCS}

Vol. $8 \mathrm{~N}^{\mathrm{o}}$ 16, Julho - Dezembro de 2016

2011, p. 195). E, se a liberdade está vinculada à ação - sendo a expressão da opinião também uma forma de ação -, é possível entender a resistência do grupo Rosa Branca, tendo em vista a impossibilidade de declarar sua opinião contrária acerca do regime e de propor mudanças. Para Hannah Arendt "os homens são livres - diferentemente de possuírem o dom da liberdade - enquanto agem, nem antes, nem depois; pois ser livre e agir são a mesma coisa" (ARENDT, 2011, p. 199).

Hannah Arendt chega a tratar um pouco da resistência alemã em Eichmann em Jerusalém. Para a filósofa, a Rosa Branca foi o único tipo de resistência - deixando de lado os "conspiradores", aqueles que planejaram o assassinato de Hitler - que sabia distinguir o certo do errado, que nunca tiveram nenhuma "crise de consciência", que não se calaram e principalmente, que tomaram uma atitude. No entanto, ela considera que a Rosa Branca se constituía um elemento isolado entre a população, pois, os que não concordavam com o governo, geralmente não tomavam nenhuma medida "prática" e conservavam seu silêncio.

Fundamental tratar aqui também da desobediência civil, igualmente trabalhada por Hannah Arendt em Crises da República. Para a autora, a desobediência civil acontece dentro de um grupo, que pode ser pequeno e dissidente da maioria, com identidade de interesses, e que resolve agir porque acredita que "os canais normais para mudanças já não funcionam, e que as queixas não serão ouvidas nem terão qualquer efeito" (ARENDT, 2010, p. 68), e, a característica do dissidente civil é a não violência. Os motivos da desobediência civil devem ser debatidos "não no campo da moral do cidadão em relação à lei, mas no campo da consciência individual e do compromisso moral da consciência" (ARENDT, 2010, p. 57.), e, os dissidentes civis são considerados como "minorias organizadas, delimitadas mais pela opinião comum do que por interesses comuns, e pela decisão de tomar posição contra a política do governo mesmo tendo razões para supor que ela é apoiada pela maioria” (ARENDT, 2010, p. 55). Neste sentido, o Rosa Branca pode ser entendido como um grupo de desobedientes civis; escolhi o termo resistência apenas porque eles se entendem dessa forma e assim o usam nos panfletos. 


\section{Revista Brasileira de História \& Ciências Sociais - RBHCS}

Vol. $8 \mathrm{~N}^{\circ}$ 16, Julho - Dezembro de 2016

Discutindo as questões morais, em Responsabilidade e Julgamento, Hannah Arendt demonstra que não é possível tratar de algo como culpa coletiva de toda a população alemã "desde Lutero a Hitler" (ARENDT, 2004, p. 83), principalmente porque, ao generalizar a culpa, ela se torna de ninguém. O regime nazista introduziu na sociedade um novo conjunto de valores e concomitantemente, um corpo jurídico ligado a esses novos valores. Ela afirma que diante do horror, de uma situação de exceção, houve um colapso quase universal de julgamento pessoal. Essa análise de Arendt me parece mais pertinente, apesar de ser o oposto do que a Rosa Branca propõe, pois os estudantes afirmavam que todos os alemães eram culpados pelo nazismo.

Arendt demonstra que os "não participantes" permaneceram com o mesmo sistema de valores - ou seja, com o mesmo julgamento de certo e errado - que eles possuíam antes de Hitler, de modo que não assassinavam porque se recusavam a viver com um assassino - eles mesmos. Desta forma, a conduta moral não está relacionada à obediência a nenhuma lei externa, o que, segundo Kant, diferencia moralidade de legalidade. Ao tratar do imperativo categórico, Kant evidencia que, se não quero contradizer a mim mesmo, devo agir de tal maneira que "a máxima de meu ato pode se tornar uma lei universal" (ARENDT, 2004, p. 133). Por isso é melhor, como demonstra Sócrates, estar em desacordo com os outros do que estar em desacordo consigo mesmo, e isto também vale para a noção de que é melhor sofrer o mal do que cometê-lo, pois "se faço o mal, sou condenado a viver junto com um malfeitor numa intimidade insuportável; nunca posso me livrar dele" (ARENDT, 2004, p. 154-155). Neste sentido, os alemães da época nazista que não eram responsáveis - como os integrantes do Rosa Branca -, não passaram por uma crise moral ou de consciência porque o mal, para eles, não era uma tentação; eles apenas preferiam morrer a ter que viver com um criminoso. Eles "nunca duvidaram que os crimes permaneceram sendo crimes mesmo se legalizados pelo governo" (ARENDT, 2004, p. 142).

Hannah Arendt faz uma reflexão acerca dos conceitos de culpa e de responsabilidade coletiva, apontando a clara diferença entre os mesmos. Para a filósofa, a culpa é um sentimento pessoal ligado, principalmente, à moralidade, enquanto a responsabilidade coletiva está inserida no campo político, dentro de uma comunidade. 


\section{Revista Brasileira de História \& Ciências Sociais - RBHCS}

Vol. $8 \mathrm{~N}^{\circ}$ 16, Julho - Dezembro de 2016

Neste sentido, é tão errado sentir culpa por algo que não fizemos de fato, como não sentir culpa por algo que fizemos. Porém, podemos sentir responsabilidade por algo que não fizemos, já que vivemos em uma comunidade e vivemos com nós mesmos. Ou seja, é o nosso dever político, enquanto comunidade, de impedir o mal; quando não o impedimos, somos responsáveis, não culpados.

"Diria que duas condições tem de estar presentes para a responsabilidade coletiva: devo ser considerado responsável por algo que não fiz, e a razão para a minha responsabilidade deve ser o fato de eu pertencer a um grupo (um coletivo), o que nenhum ato voluntário meu pode dissolver [...] Esse tipo de responsabilidade, na minha opinião, é sempre política [...] Todo governo assume a responsabilidade pelos atos e malfeitorias de seus predecessores, e toda nação pelos atos e malfeitorias do passado" (ARENDT, 2004, p. 216-217).

Outro autor fundamental para as questões de culpa e responsabilidade - que dialoga muito com Hannah Arendt - é o sociólogo Zygmunt Bauman. Em Modernidade e Holocausto, Bauman propõe a teoria de que o Holocausto é fruto da Modernidade e que não devemos tratar o comportamento imoral como um desvio da norma ou algo que seja inserido fora da sociedade. Para Bauman, a conduta moral deve existir independente do fator externo, ou seja, independente da sociedade em que estamos inseridos: "Mesmo se condenada pelo grupo - por todos os grupos, aliás - a conduta individual deve ainda ser moral; uma ação recomendada pela sociedade - mesmo por todo o conjunto da sociedade em uníssono - pode ainda assim ser imoral" (BAUMAN, 1998, p. 206). A capacidade de julgamento de distinguir certo e errado é algo que deve se basear além da consciência coletiva da sociedade e, enxergar os nazistas como loucos e sádicos que fizeram tudo por terem uma "doença", diminui a culpa e a carga de responsabilidade do que realmente precisa ser analisado:

"Enquanto a moralidade for entendida como produto social e explicada em termos causais por referência a mecanismos que, se funcionam adequadamente, garantem seu 'abastecimento constante', os eventos que ofendem os difusos, mas arraigados sentimentos morais e desafiam a concepção comum do bem e do mal (da conduta própria ou imprópria) tenderão a ser vistos como resultado de uma falha ou má administração da 'indústria moral'. (...) O comportamento imoral é então teorizado como 'desvio' da norma e, em última análise, da deficiência ou imperfeição dos mecanismos sociais destinados a exercer tais pressões" (BAUMAN, 1998, p. 202-203). 


\section{Revista Brasileira de História \& Ciências Sociais - RBHCS}

Vol. $8 \mathrm{~N}^{\circ}$ 16, Julho - Dezembro de 2016

Para Bauman, a responsabilidade pelas ações morais repousa no indivíduo e cabe a ele a capacidade de resistir à pressão da sociedade para fazer algo que ele pode considerar como errado. O que o nazismo conseguiu atingir com sucesso, foi a produção social da distância entre os indivíduos de modo a eliminar essa noção de responsabilidade na maioria das pessoas. A divisão de tarefas e a maneira burocrática como o processo da Solução Final foi levado, criou uma enorme distância entre vitimadores e vítimas, e as câmaras de gás reduziram o "papel do matador ao "funcionário sanitário" e isso foi observado no julgamento de Eichmann por Hannah Arendt. Além disso, Eichmann também acreditava estar sobre as ordens de outras pessoas e assim, segundo Bauman, todos os membros da organização estavam convencidos, de modo a criar uma responsabilidade flutuante (BAUMAN, 1998, p. 190191): todos estavam convencidos de estar sobre as ordens de outra pessoa. A organização inteira girava em torno de eliminar essa responsabilidade.

Com teorias muito similares a de Hannah Arendt, o que Bauman tenta mostrar é que o Holocausto foi produto de uma civilização normal, com seres humanos normais e regulares, que tinham família, amigos e que pensavam apenas estar cumprindo o seu dever, tão inseridos estavam naquela burocracia totalitária. Ele argumenta que a Solução Final foi um processo de encontrar soluções "racionais" para vários "problemas" à medida que eles chegavam, e que esse tipo de atitude administrativa e burocrática é algo marcante da Modernidade: “A verdade é que todos os 'ingredientes' do Holocausto todas as inúmeras coisas que o tornaram possível - foram normais (...) no sentido de plenamente acompanhar tudo o que sabemos sobre nossa civilização, seu espírito condutor, suas prioridades, sua visão imanente do mundo" (BAUMAN, 1998, p. 27).

\section{Conclusão}

Pretendia com este artigo contar um pouco da história do grupo Rosa Branca, assim como apresentar uma análise mais profunda de seus conceitos. Além disso, tentei fazer uma análise da resistência ao governo de Hitler, procurando fugir de um viés dicotômico de "bons alemães" X "nazistas". Os resistentes muitas vezes se inserem na 


\section{Revista Brasileira de História \& Ciências Sociais - RBHCS}

Vol. $8 \mathrm{~N}^{\circ}$ 16, Julho - Dezembro de 2016

mesma bandeira de defensores da liberdade contra o mal, sem levar em conta as ideologias e constituições políticas diferenciadas existentes nesse tipo de momento histórico. A resistência se deu por muitos motivos, e no caso da Rosa Branca, podemos observar que não se tratava de uma resistência libertária ou em defesa de uma democracia e de direitos iguais. O crime contra o povo judeu não foi abordado por eles de maneira clara ou aprofundada. $\mathrm{O}$ que seria feito caso eles tivessem tido sucesso em derrubar o regime de Hitler, também não é tratado nos panfletos. Provavelmente não veriam com maus olhos um governo conservador, desde que lhes fosse assegurada a liberdade de expressão e de pensamento, que tanto demandavam.

A recusa por uma crítica historiográfica da resistência se deve principalmente pela presença muito forte da memória, e de historiadores militantes, que tendem a idealizar os resistentes sem considerar os objetivos, identificações e as diferentes formas de resistir ao autoritarismo. Como Marcos Napolitano aponta, esse tipo de discurso pode levar a um elogio ou censura ao passado, sem de fato compreendê-lo (NAPOLITANO, 2011). No caso do nazismo isso é ainda mais preocupante, pois abre a possibilidade para dizer que os alemães que não resistiram são culpados pelo que aconteceu. Compreender o passado, principalmente o passado traumático, é também criticar a memória sobre esse passado. Segundo Hannah Arendt:

"O perdão não é condição nem consequência da compreensão. Perdoar (com certeza, uma das maiores capacidades humanas e talvez a ação humana mais ousada, na medida em que tenta o aparentemente impossível, a saber, desfazer o que foi feito, e consegue criar um novo começo quando tudo parecia ter chegado ao fim) é uma ação única e culmina num gesto único. Compreender é infindável e, portanto, não pode gerar resultados definitivos. É a maneira especificamente humana de viver, pois todo indivíduo precisa se sentir conciliado com um mundo onde nasceu como estranho e onde sempre permanece como estranho, na medida de sua singularidade única. A compreensão começa com o nascimento e termina com a morte. Na medida em que o surgimento dos governos totalitários é o acontecimento central de nosso mundo, compreender o totalitarismo não é desculpar nada, mas nos conciliar com um mundo onde tais coisas são possíveis. " (ARENDT, 2008, p. 331)

\section{REFERÊNCIAS BIBLIOGRÁFICAS}


Revista Brasileira de História \& Ciências Sociais - RBHCS

Vol. $8 \mathrm{~N}^{\circ}$ 16, Julho - Dezembro de 2016

ARENDT, Hannah. Origens do Totalitarismo. São Paulo: Companhia das Letras, 1989. . Entre o passado e o futuro. São Paulo: Perspectiva, 2011.

. Eichmann em Jerusalém: um relato sobre a banalidade do mal.

São Paulo: Companhia das Letras, 1999.

. Homens em tempos sombrios. São Paulo: Companhia das Letras,

2008.

. Responsabilidade e Julgamento. São Paulo: Companhia das

Letras, 2004.

. Crises da República. São Paulo: Perspectiva, 2010.

. Compreender: formação, exílio e totalitarismo (ensaios). São

Paulo: Companhia das Letras; Belo Horizonte: Editora UFMG, 2008.

. A promessa da política. Rio de Janeiro: DIFEL, 2010.

BAUMAN, Zygmunt. Modernidade e Holocausto. Rio de Janeiro: Zahar, 1998.

BIGNOTTO, Newton; MORAES, Eduardo Jardim de (orgs). Hannah Arendt: diálogos, reflexões, memórias. Belo Horizonte: Editora UFMG, 2011.

DUMBACH, Annette; NEWBORN, Jud. Sophie Scholl and the White Rose. USA: Oneworld, 2007.

HOFFMAN, Peter. The History of the German resistance, 1933-1945. $3^{\text {rd }}$ English ed. Canada: McGill-Queen's University Press, 2001.

ISAAC, Jeffrey C. Arendt, Camus, and the modern rebellion. Yale University Press, 1992.

JASMIN, Marcelo Gantus. História dos conceitos e teoria política e social: referências preliminares. Revista Brasileira de Ciências Sociais: vol. 20, $\mathrm{n}^{\circ} .57$, fevereiro de 2005.

JENS, Inge. At the heart of the White Rose: Letters and diaries of Hans and Sophie Scholl. USA: Harper \& Row Publishers, 1987.

KERSHAW, Ian. Hitler, the Germans, and The Final Solution. Yale University Press, 2008.

KOSELLECK, Reinhard. Futuro passado: contribuição à semântica dos tempos históricos. Rio de Janeiro: Contraponto: Ed. PUC Rio, 2006. 
Revista Brasileira de História \& Ciências Sociais - RBHCS

Vol. $8 \mathrm{~N}^{\circ}$ 16, Julho - Dezembro de 2016

LACAPRA, Dominick. Representing the Holocaust: history, theory, trauma. Cornell University Press, 1994.

. History and memory after Auschwitz. Cornell University

Press, 1998.

LEFORT, Claude. A invenção democrática: Os limites da dominação totalitária. Belo Horizonte: Autêntica Editora, 2011.

MANN, Thomas. Ouvintes alemães! Discursos contra Hitler (1940-1945). Rio de Janeiro: Jorge Zahar Ed., 2009.

NAPOLITANO, Marcos. Coração civil: arte, resistência e lutas culturais durante o regime militar Brasileiro (1964-1980). Tese (concurso de Livre-Docência junto ao Departamento de História). Universidade de São Paulo, SP, 2011.

NICOSIA, Francis R.; STOKES, Lawrence D. Germans Against Nazism: Essays in honour of Peter Hoffmann; Nonconformity, opposition and resistance in the Third Reich. New York/Oxford: 1990.

PROST, Antoine. Doze Lições Sobre a História. Belo Horizonte: Autêntica Editora, 2008.

SCHOLL, Inge. The White Rose: Munich, 1942-1943. New York: Wesleyan University Press, 1983.

SCHOLL, Inge. A Rosa Branca: A história dos estudantes alemães que desafiaram o nazismo. São Paulo: Editora 34, 2013.

Recebido em Fevereiro de 2016 Aprovado em Novembro de 2016 